\title{
Active normal faults and submarine landslides in the Keelung Shelf off NE Taiwan
}

\author{
Ching-Hui Tsai ${ }^{1}$, Chi-Lo Huang ${ }^{2}$, Shu-Kun Hsu ${ }^{1,2, *}$, Wen-Bin Doo ${ }^{1}$, Shiao-Shan Lin ${ }^{2}$, Shiou-Ya Wang ${ }^{2}$, \\ Jing-Yi Lin ${ }^{2}$, and Chin-Wei Liang ${ }^{1}$ \\ ${ }^{1}$ Center for Environmental Studies, National Central University, Taoyuan City, Taiwan \\ ${ }^{2}$ Department of Earth Sciences, National Central University, Taoyuan City, Taiwan
}

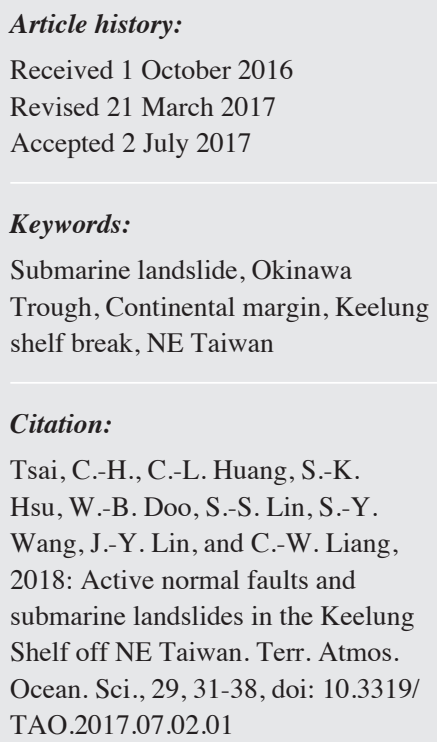

\begin{abstract}
The westernmost Okinawa Trough back-arc basin is located to the north of the Ryukyu islands and is situated above the northward dipping Ryukyu subducted slab. In the northern continental margin of the Okinawa Trough, the continental slope between the Keelung Valley and the Mein-Hua Submarine Canyon shows a steep angle and future slope failures are expected. The question is how slope failures will proceed? A sudden deep-seated slump or landslide would probably cause local tsunami and hit northern coast of Taiwan. To understand the probable submarine landslides, we conducted multi-channel seismic reflection, sub-bottom profilers, and multi-beam bathymetry surveys off NE Taiwan. Two general trends of shallow crustal faults are observed. The NE-SW trending faults generally follow the main structural trend of the Taiwan mountain belt. These faults are products of inversion tectonics of reverse faults from the former collisional thrust faults to post-collisional normal faults. Another trend of roughly E-W faults is consistent with the current N-S extension of the southern Okinawa Trough. The fault offsets in the eastern portion of the study area are more pronounced. No obvious basal surface of sliding is found beneath the continental margin. We conclude that the movement of the submarine landslides in the Keelung Shelf off northeastern Taiwan could be in a spread type. The submarine landslides mainly occur in the continental slope area and it is more obvious in the east than in the west of the Keelung Shelf.
\end{abstract}

\section{INTRODUCTION}

Owing to the dense population (more than ten million people) in northern Taiwan, natural hazards from potential large earthquakes, submarine landslides or induced tsunamis in the near shore of northern Taiwan are large menaces to the northern coast of Taiwan. Especially, two nuclear power plants (red squares in Fig. 1) are located in the northern coast of Taiwan. There are three NW-trending sub-parallel major submarine canyons run from the East Sea continental shelf into Okinawa trough in the offshore area of northeastern Taiwan; from west to east, they are Keelung Valley, MienHua Submarine Canyon, and North Mien-Hua Submarine Canyon (Fig. 1). Based on the existing bathymetric map, the continental slope of the Keelung Shelf located between the
Keelung Valley and Mien-Hua Submarine Canyon display a steep angle of $\sim 6^{\circ}$ which is much steeper than the continental slope angle of $\sim 1.5^{\circ}$ in the area to the northeast of the Mien-Hua Submarine Canyon (Fig. 1). The continental slope tendency of the Keelung Shelf implies that disastrous submarine landslides may occur near the shelf break and generate tsunamis affecting the coastal area of northern Taiwan. For that, we study the topographic features and subsurface geological structures across the Keelung Shelf in order to better understand the potential active faults, submarine landslides and tectonic mechanism in the northern margin of the westernmost Okinawa Trough.

\section{TECTONIC SETTING}

Taiwan comprises a late Cenozoic mountain belt formed by the collision between the Philippine Sea Plate

\footnotetext{
* Corresponding author

E-mail:hsu@ncu.edu.tw
} 


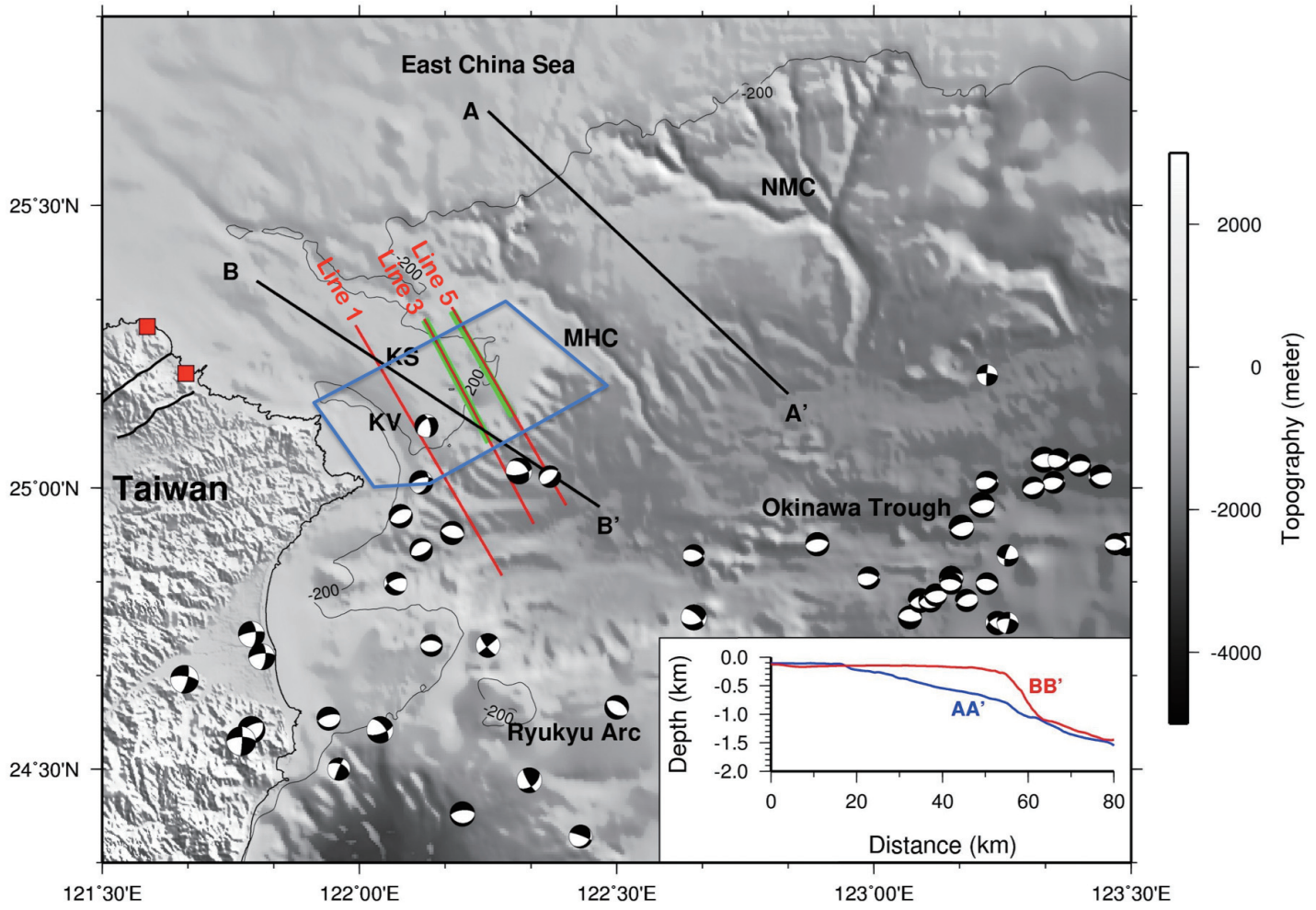

Fig. 1. The topography of the southern Okinawa Trough and the northern Taiwan area. The multi-beam survey area is indicated by the blue polygon. The red lines indicated the seismic reflection profiles and the green lines indicate the sub-bottom profiler data used in this study. KV: Keelung Valley. MHC: Mien-Hua Submarine Canyon. NMC: North Mien-Hua Submarine Canyon. KS: Keelung Shelf. The crustal earthquake focal mechanisms are from global CMT solutions from earthquakes of magnitude greater than 4 and shallower than $30 \mathrm{~km}$ from 1976 - 2015 . It is noted that the Keelung Shelf and its contiguous continental slope area exhibit normal faulting stress regime. The bathymetric contour of $200 \mathrm{~m}$ is plotted for reference. The bathymetric profiles AA' and BB' across different continental slope areas are plotted in the right-bottom panel. The profile BB' across the Keelung Shelf and its contiguous continental slope reveals a steeper slope and implies a highly potential area of slope failures.

and the Eurasian Plate (Ho 1988; Teng 1990; Sibuet and Hsu 2004). The most active uplift of the Taiwan mountain belt is occurring in central Taiwan, while the northern Taiwan mountain belt has begun to collapse (Teng 1996; Lo and Hsu 2005). Volcanoes are also well developed in the onshore and offshore of northern Taiwan (e.g., Wang et al. 1999; Hsu et al. 2001; Lin et al. 2004). The deformed orogenic strata and overlying Pliocene-Quaternary andesitic volcanic and extensional structures of the northeastern Taiwan can be traced offshore northern Taiwan (Huang et al. 1992; Deffontaines et al. 2001).

The offshore area of the northeastern Taiwan is linked to a tectonic transition among the post-collision mountain belt, the Chinese continental shelf and the north-southward extension of the Okinawa Trough backarc basin, located to the north of the Ryukyu Arc (Sibuet et al. 1998; Sibuet and Hsu 2004). The post-collisional context has also coincided with the westward prolongation of the Ryukyu subduction zone. The southern Okinawa Trough is actively extended because the subducting slab of the westernmost Philippine Sea Plate has decoupled from the overriding plate (Hsu 2001; Wu et al. 2010). Overall, the offshore area of the northern Taiwan is under an extensional regime, as indicated by the crustal earthquakes with normal faulting mechanism (Fig. 1) (e.g., Kao et al. 1998). Because of the intensive extension in the offshore area of the northern Taiwan and the southernmost Okinawa Trough backarc basin, the slope failures in the continental slope adjacent to the Keelung Shelf can be enhanced. The repeatedly earthquake-induced submarine landslide turbidities were recorded in the southern Okinawa Trough based on the sediment analyses from the cores in the area (Huh et al. 2004).

\section{DATA PROCESSING AND RESULTS}

\subsection{Multi-Beam Bathymetry}

To understand the seafloor geomorphic features of the Keelung Shelf, we have conducted a multi-beam survey in the area as shown by the blue rectangle in Fig. 1. The result of bathymetry is shown in Fig. 2a. The linear features of the seafloor gullies are interpreted as some structural faults or topographic erosions. In either case, their orientations are roughly in the NE-SW or W-E direction (Fig. 2b). Probably due to a high sedimentation rate from discharge of the Keelung Valley in the SW of the study area, the linear features become unclear. These structural orientations are generally 


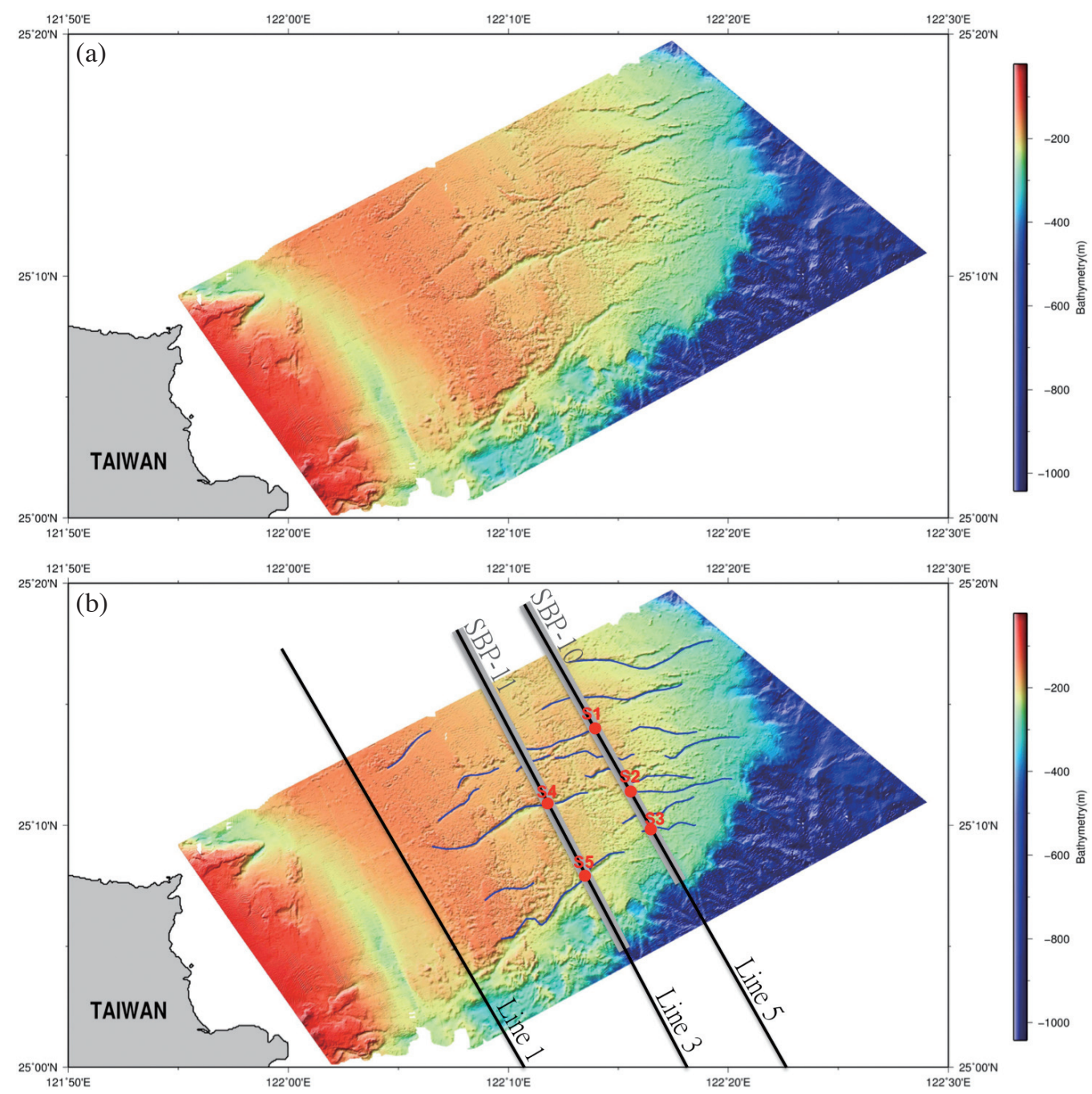

Fig. 2. (a) The multi-beam bathymetric map of the Keelung Shelf. (b) Some obviously morphologic features (or gullies) are indicated by blue lines. Note that the linear features are generally in NE-SW trend or in E-W trend. The gray lines indicate the sub-bottom profilers shown in Figs. 6 and 7, respectively. Lines 1,3, and 5 are tracks of seismic profiles. Symbols S1 to S5 indicate morphologic offsets that are described in detail in Figs. 6 and 7.

coherent with the inherited NE-SW trend of the Taiwan mountain belt or with the W-E trending normal faults due to the current Okinawa Trough backarc extension. Spatially, the structures (or gullies) (blue lines in Fig. 2b) seem to develop better in the east than in the west of the Keelung Shelf. Some bathymetric scarps associated with seafloor failures occur near the shelf break, indicating current active gravity-driven landslides.

\subsection{Multichannel Reflection Seismic Profiles}

To verify whether the bathymetric lineations are associated with structural faults or not, we have conducted a 24-channel reflection seismic survey across the Keelung Shelf and its contiguous continental slope. Three migrated seismic profiles, indicated by red lines in Fig. 1, are shown in Figs. 3 - 5. Two clear stratigraphic sequence boundaries at $\sim 1 \mathrm{~s}$ t.w.t. (two-way-travel-time) and $\sim 1.5-2 \mathrm{~s}$ t.w.t are marked by orange and purple color respectively. Based on Figs. 3 - 5, three structural characteristics can be derived. Firstly, with respect the upper flat-lying strata, the folding or thrusting at the basement are pronounced in all the profiles. It indicates that the Keelung Shelf had been compressed, possibly in late Miocene during early Taiwan arccontinental collision (Teng 1990). Those structures could be inherited from the former collision between the Luzon Arc and the Asian continental margin. Secondly, as indicated by $\mathrm{S} 1$ to S5 in seismic profiles lines 2 or 3 respectively (cf. Figs. 2b, 4, and 5), the seafloor gullies are associated with normal faults. The normal faults have developed better in the shallow strata in the east than in the west. Because the extensional features at seafloor can connect to the inherited thrusts at basement, we can infer that the Keelung Shelf has experienced a tectonic transition from plate collision to 

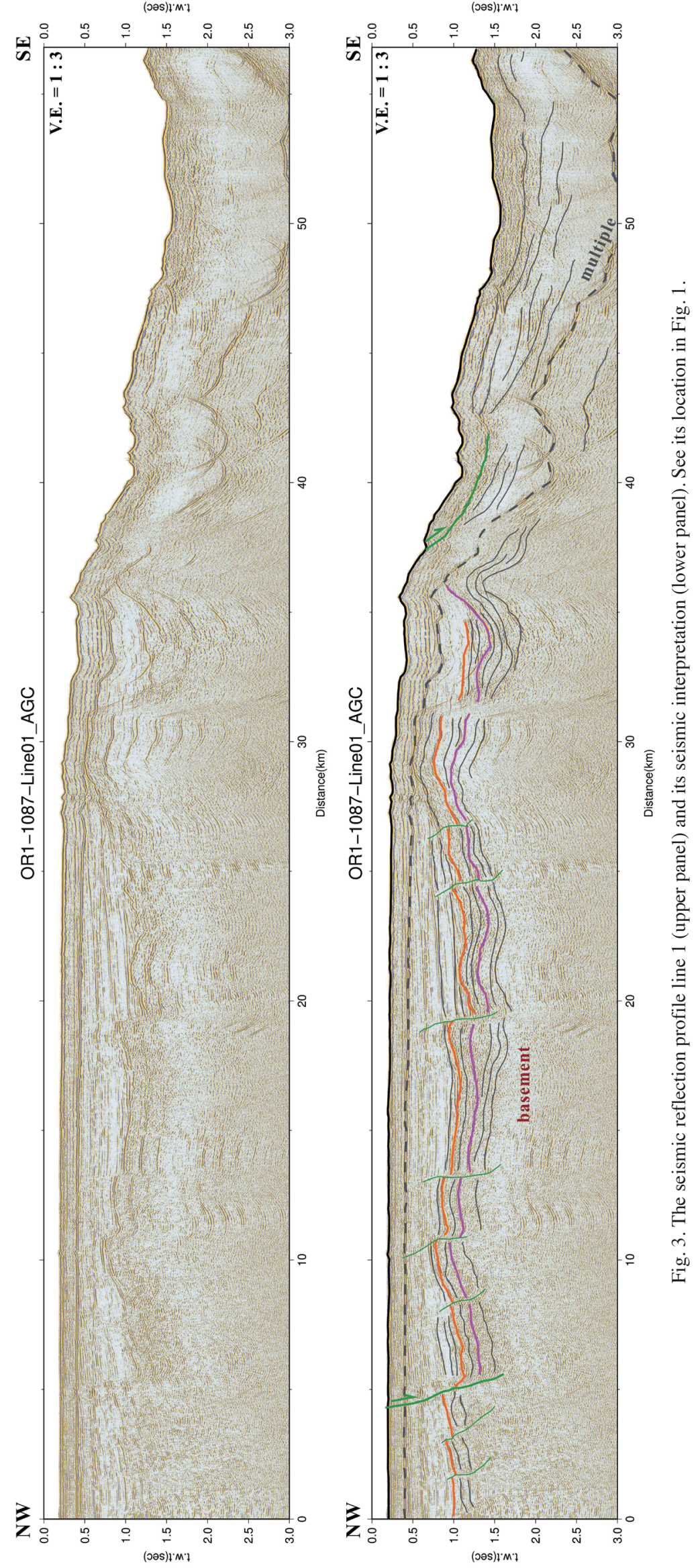


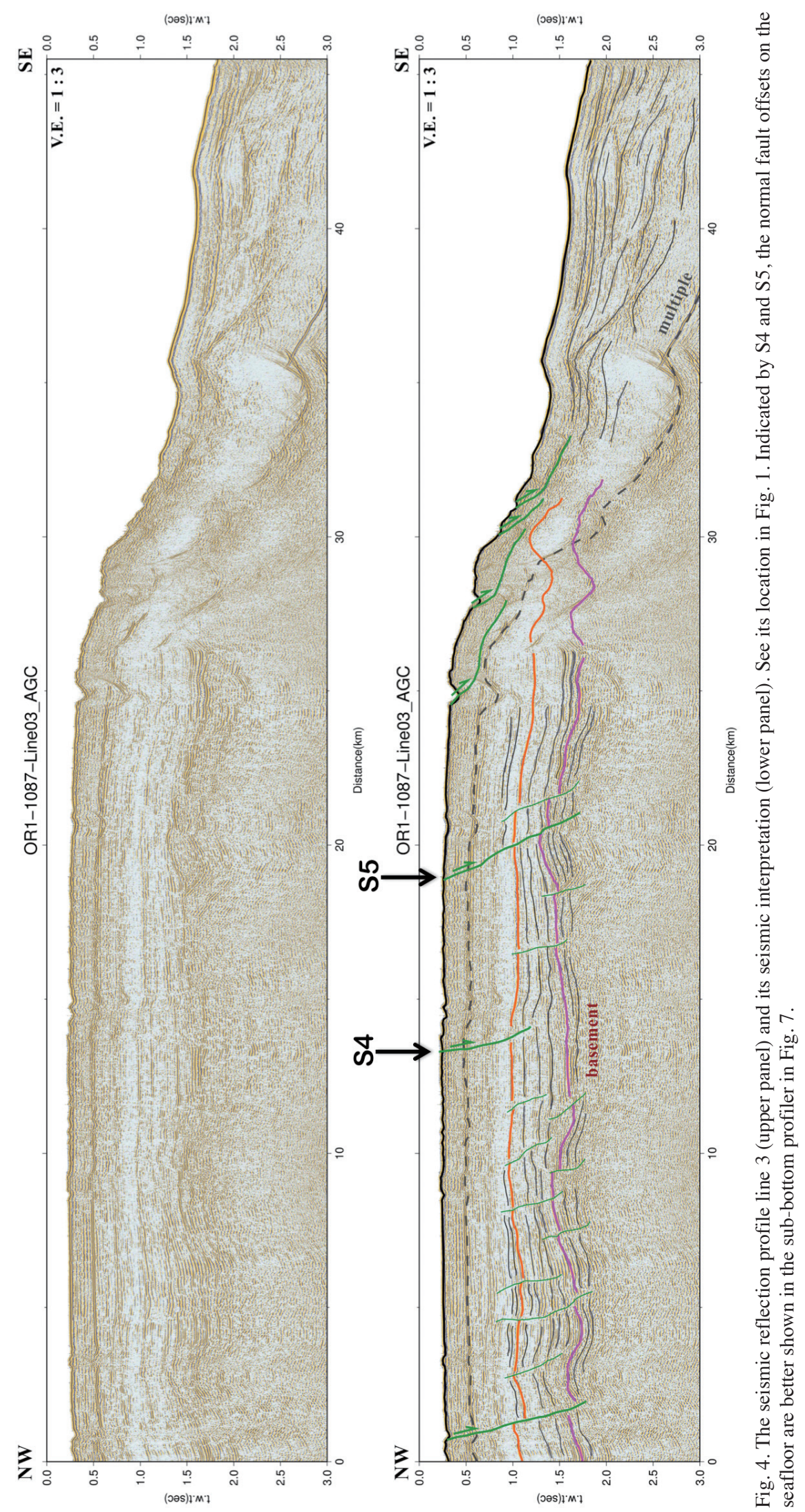



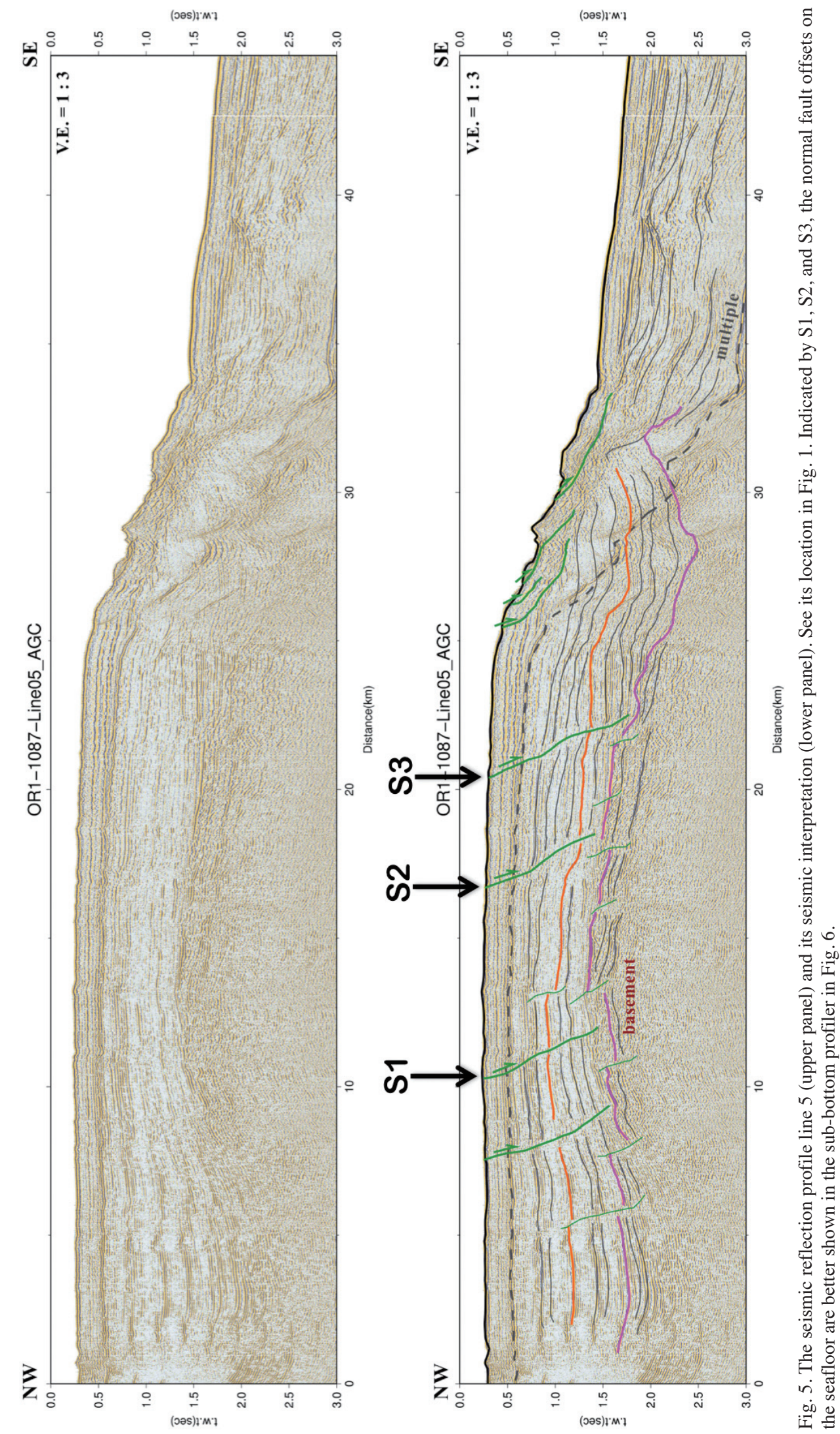
post-collision. Furthermore, the submarine landslides in the continental slope area have occurred more obviously in the east than in the west. It suggests that the modern slope failures are not equally distributed in the Keelung Shelf area. It implies that the backarc extension due to the Philippine Sea Plate subduction beneath the south Ryukyu Arc is more intensively in the east than in the west. Thirdly, the normal faults in the Keelung Shelf cut across the marked seismic sequences but they do not connect with any obvious décollement in the seismic profiles. It suggests that those extensional faults could be in a spread mode and the extensional force is ascribed to the Okinawa Trough backarc rifting. Because there is no sliding surface beneath the continental shelf, a large submarine landslide whose headwall far from the shelf break may be excluded.

\subsection{Sub-Bottom Profiles}

We have conducted a deep-towed sub-bottom profiler survey along the seismic lines 5 and 3 (SBP-10 and SBP 11 in Figs. 1 and 2b). The acoustic source frequency is 1 $10 \mathrm{kHz}$, which allows us to examine better the near-seafloor structures. As shown in Figs. 6 and 7, the data of sub-bottom profilers indicate that the shallow sedimentary layers have been under significant erosion. The seabed erosion has caused rough relief. However, the $5-15 \mathrm{~m}$ stratum offsets at

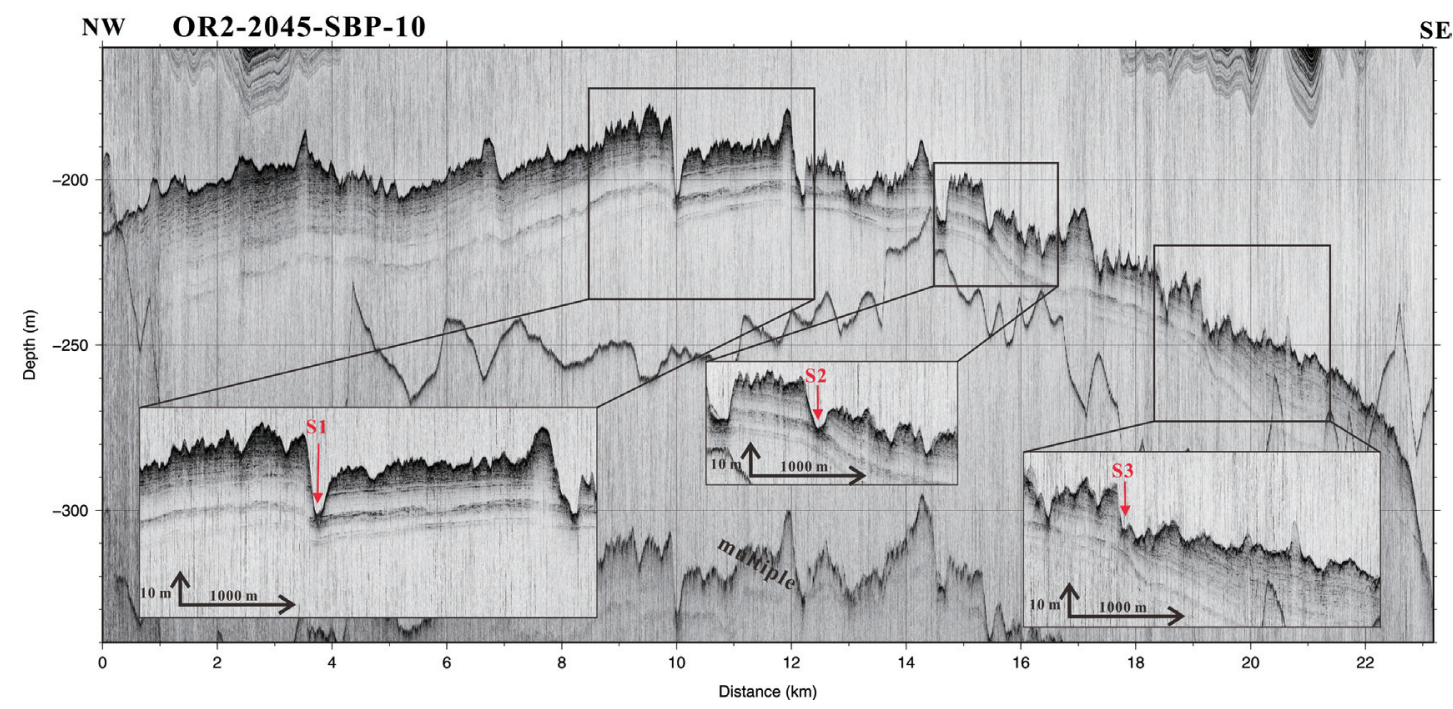

Fig. 6. The acoustic image of the sub-bottom profile SBP10 along the seismic profile line 5 in the Keelung Shelf. It is noted that the seabed is eroded and the gullies at S1, S2, and S3 have vertical offsets, corresponding to the outcrops of the normal faults shown in the seismic profile in Fig. 5 .

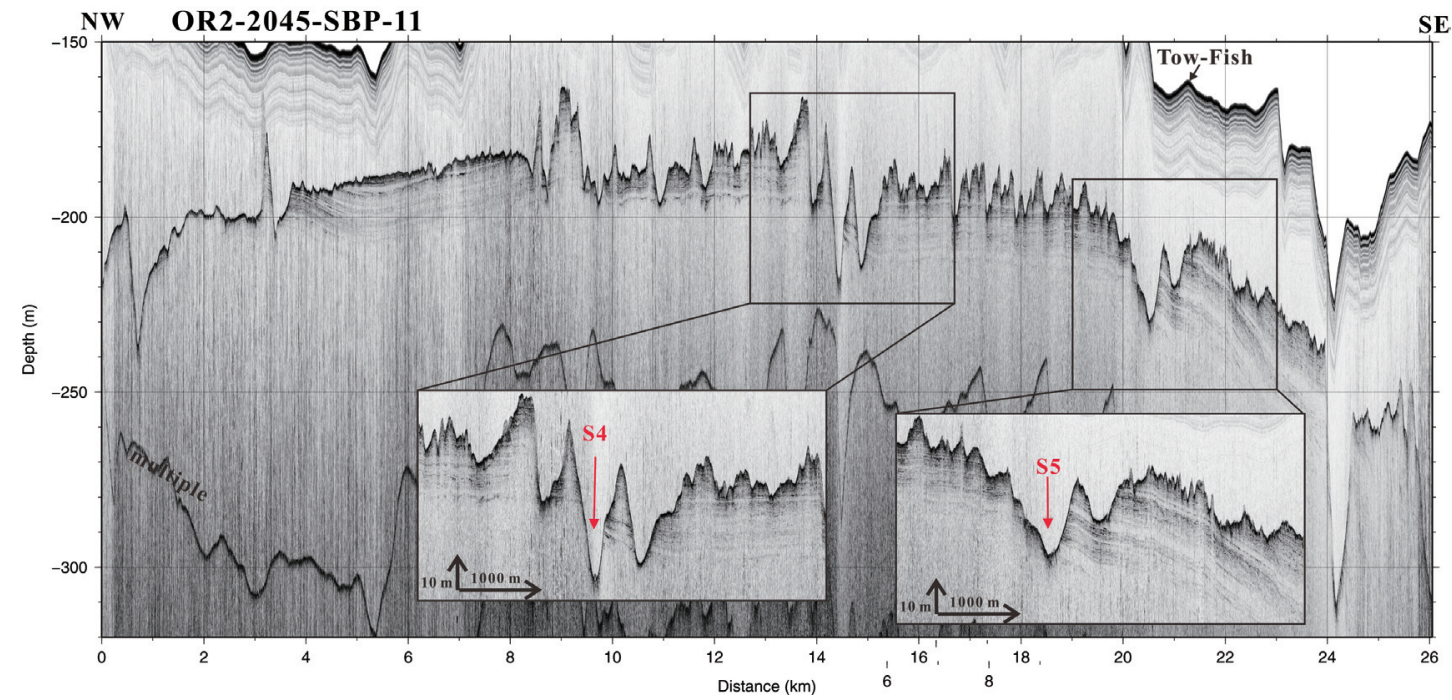

Fig. 7. The acoustic image of the sub-bottom profile SBP11 along the seismic profile line 3 in the Keelung Shelf. It is noted that the seabed is eroded and the gullies at S4 and S5 have vertical offsets, corresponding to the outcrops of the normal faults shown in the seismic profiles in Fig. 4. 
locations S1, S2, S3, S4, and S5 in Fig. $2 \mathrm{~b}$ can be also recognized in the sub-bottom profiles (Figs. 6 and 7). The vertical offsets at $\mathrm{S} 1, \mathrm{~S} 2$, and $\mathrm{S} 3$ could reach $\sim 10 \mathrm{~m}$, slightly greater than those at S4 and S5. It indicates also that the vertical offsets due to the tensional subsidence are greater in the eastern side of the Keelung Shelf than in the western side.

\section{CONCLUSION}

If we consider the continental slope angle of $\sim 1.5^{\circ}$ between the Mien-Hua Submarine Canyon and the North Mien-Hua Submarine stands for a stable slope angle, the continental slope angle of $\sim 6^{\circ}$ between the Keelung Valley and the Mien-Hua Submarine Canyon implies a rather unstable slope. The potential slope failures may generate a local tsunami and affect the northeast coast of Taiwan. Our marine geophysical data show that there is a dense distribution of the NE-SW and E-W trending faults in the Keelung Shelf. These normal faults could reach $\sim 2$ s t.w.t.; whereas, no obvious sliding surface (décollement) is found beneath the continental shelf. A spread type of the submarine landslide movement in the Keelung Shelf is thus suggested. The Keelung Shelf has experienced a tectonic transition from plate collision to post-collision. Currently, more normal faults are distributed in the eastern side of the Keelung Shelf and their vertical offsets of shallow strata are slightly larger. The submarine landslides have mainly occurred at the continental slope, especially close to the shelf break. We tend to interpret that submarine landslides in the Keelung Shelf occurs gradually from east to west and there is a seldom chance that a slope failure happens for the whole Keelung Shelf mass. However, future core sampling at the foot of the continental slope may help clarify the submarine landslide history.

Acknowledgements We thank the crew of the R/V OR1 and R/V OR2 for their efforts in collecting multi-channel seismic reflection and multi-beam data, respectively. We appreciate the valuable comments from Prof. Benoit Deffontaines, Dr. Jian-Cheng Lee and Prof. Don Su. We acknowledge the research grant from the Ministry of Science and Technology (MOST) of Taiwan.

\section{REFERENCES}

Deffontaines, B., C.-S. Liu, J. Angelier, C.-T. Lee, J.-C. Sibuet, Y.-B. Tsai, S. Lallemand, C.-Y. Lu, C.-S. Lee, S.-K. Hsu, H.-T. Chu, J.-C. Lee, E. Pathier, R.-F. Chen, C.-T. Cheng, C.-W. Liao, C.-C. Lin, and H.-H. Hsu, 2001: Preliminary neotectonic map of onshoreoffshore Taiwan. Terr. Atmos. Ocean. Sci., 12, 339349, doi: 10.3319/TAO.2001.12.S.339(T). [Link]

Ho, C. S., 1988: An Introduction to the Geology of Taiwan: Explanatory Text of the Geological Map of Taiwan (Second Edition), Central Geological Survey, Ministry of Economic Affairs, Taipei, Taiwan, 192 pp.

Hsu, S.-K., 2001: Lithospheric structure, buoyancy and coupling across the southernmost Ryukyu subduction zone: An example of decreasing plate coupling. Earth Planet. Sci. Lett., 186, 471-478, doi: 10.1016/s0012821x(01)00261-8. [Link]

Hsu, S.-K., J.-C. Sibuet, and C.-T. Shyu, 2001: Magnetic inversion in the East China Sea and Okinawa Trough: Tectonic implications. Tectonophysics, 333, 111-122, doi: 10.1016/s0040-1951(00)00270-5. [Link]

Huang, S. T., H. H. Ting, R. C. Chen, W. R. Chi, C. C. Hu, and H. C. Shen, 1992: Basinal framework and tectonic evolution of offshore northern Taiwan. Petrol. Geol. Taiwan, 27, 47-72.

Huh, C. A., C. C. Su, W. T. Liang, and C. Y. Ling, 2004: Linkages between turbidites in the southern Okinawa Trough and submarine earthquakes. Geophys. Res. Lett., 31, L12304, doi: 10.1029/2004g1019731. [Link]

Kao, H., S.-S. Shen, and K.-F. Ma, 1998: Transition from oblique subduction to collision: earthquakes in the southernmost Ryukyu arc-Taiwan region. J. Geophys. Res., 103, 7211-7229, doi: 10.1029/97jb03510. [Link]

Lin, J.-Y., S.-K. Hsu, and J.-C. Sibuet, 2004: Melting features along the western Ryukyu slab edge (northeast Taiwan): Tomographic evidence. J. Geophys. Res., 109, B12402, doi: 10.1029/2004JB003260. [Link]

Lo, C.-L. and S.-K. Hsu, 2005: Earthquake-induced gravitational potential energy change in the active Taiwan orogenic belt. Geophys. J. Int., 162, 169-176, doi: 10.1111/j.1365-246x.2005.02634.x. [Link]

Sibuet, J.-C. and S.-K. Hsu, 2004: How was Taiwan created? Tectonophysics, 379, 159-181, doi: 10.1016/j. tecto.2003.10.022. [Link]

Sibuet, J.-C., B. Deffontaines, S.-K. Hsu, N. Thareau, J.P. Le Formal, and C.-S. Liu, 1998: Okinawa Trough backarc basin: Early tectonic and magmatic evolution. J. Geophys. Res., 103, 30245-30267, doi: 10.1029/98jb01823. [Link]

Teng, L. S., 1990: Geotectonic evolution of late Cenozoic arc-continent collision in Taiwan. Tectonophysics, 183, 57-76, doi: 10.1016/0040-1951(90)90188-e. [Link]

Teng, L. S., 1996: Extensional collapse of the northern Taiwan mountain belt. Geology, 24, 949-952, doi: 10.113 0/0091-7613(1996)024<0949:ecotnt>2.3.co;2. [Link]

Wang, K.-L., S.-L. Chung, C.-H. Chen, R. Shinjo, T. F. Yang, and C.-H. Chen, 1999: Post-collisional magmatism around northern Taiwan and its relation with opening of the Okinawa Trough. Tectonophysics, 308, 363376, doi: 10.1016/s0040-1951(99)00111-0. [Link]

Wu, W.-N., H. Kao, S.-K. Hsu, C.-L. Lo, and H.-W. Chen, 2010: Spatial variation of the crustal stress field along the Ryukyu-Taiwan-Luzon convergent boundary. J. Geophys. Res., 115, B11401, doi: 10.1029/2009jb007080. [Link] 